\title{
Association between imaging and clinical findings in mandibular third molar surgeries
}

\author{
Associação entre achados clínicos e imaginológicos em cirurgias de \\ terceiros molares inferiores
}

Marcelo Bonifácio da Silva Sampieri
Danilo da Silva Correa
Francisca Lívia Parente Viana $a^{* * *}$
Thaís Sumie Nozu Imada ${ }^{* * * *}$
Josfran da Silva Ferreira Filho $o^{* * * * *}$
Eduardo Sant'Ana ${ }^{* * * * *}$

\section{Abstract}

Objective: it is important to evaluate the position and establish the third molar relationship with the mandibular canal to minimize the risk of nerve injury and assist in planning the extraction of this tooth. The panoramic radiograph is the standard diagnostic tool for this purpose. However, if it indicates a close relationship between the third molar and the mandibular canal, further investigation using cone beam computed tomography (CBCT) may be recommended to check the three-dimensional relationship between the tooth and the mandibular canal. Thus, this study aimed to correlate the clinical findings (observed in third molar surgeries) to imaging findings (observed in panoramic radiographs and CBCT). Subjects and method: after the extraction of 20 mandibular third molars, the panoramic radiograph and the cone beam computed tomography were analyzed. Then, the surgical findings were correlated to the image findings. Results: It was observed that the radiographic finding type 2 (darkening of roots) observed in the panoramic radiograph presented a greater relation to the absence of cortical bone between the mandibular canal and the third molar (СВCT finding), with statistical significance $(p<0.05)$. Conclusions: Based on the findings obtained in this study, it may be concluded that CBCT would be best used in the surgical planning, when the panoramic radiograph clearly suggests a risk. Moreover, the panoramic radiograph may continue to be used for the planning of third molar extractions.

Keywords: Cone beam computed tomography. Panoramic radiograph. Third molar. Unerupted tooth.

\section{Introduction}

Third molar surgeries require training, because accidents and complications may occur. One of these complications is the damage to the inferior alveolar nerve (IAN). The risk of injury varies from $0.4 \%$ to $6 \% \%^{1,2}$. It is important to evaluate and establish the relationship between mandibular third molar (MTM) and mandibular canal (MC) to minimize the risk of injury to the nerve. The panoramic radiograph (PR) is the standard tool for this purpose $^{3-5}$. If the PR indicates a close relationship between MTM and MC, a further investigation using computed tomography may be recommended to verify the three-dimensional relation between the tooth and the mandibular canal ${ }^{3-5}$.The disadvantages of computed tomography are the high radiation $\operatorname{dose}^{6}$ and the cost compared with the PR. However, the cone beam computed tomography (CBCT) reduces the radiation dose, offers a high special resolution, and requires a smaller space in dental offices. The CBCT provides an improved quality image of teeth and adjacent structures when compared with computed tomography. The CBCT seems to be the imaging exam that is more indicated to identify the relationship between the roots of MTM and IAN ${ }^{7,8}$. Currently, there are studies comparing the ability of $\mathrm{PR}$ and CBCT in determining the relationship between the roots of MTN and the $\mathrm{MC}^{9-12}$. However, few studies have used the gold standard in this me-

Professor, Department of Stomatology, School of Dentistry of Sobral, Federal University of Ceará (UFC), Sobral, Ceará, Brazil.

MSc, DDS, Federal University of São Paulo (FOBUSP), São Paulo, São Paulo, Brazil.

MSc, DDS, Federal University of Ceará (UFC), Fortaleza, Brazil.

PhD, Dentist, School of Dentistry of Bauru, University of São Paulo (FOBUSP), Bauru, São Paulo, Brazil.

Student, Oral and Maxillofacial Anatomy and Traumatology League, University of Ceará (UFC), Sobral, Ceará, Brazil.

Student, Oral and Maxillofacial Anatomy and Traumatology League, University of Ceará (UFC), Sobral, Ceará, Brazil. 
thod, meaning they evaluated the imaging findings without correlation to surgical outcomes.

\section{Subjects and method}

The present study was performed in the School of Dentistry of Bauru (University of São Paulo, SP, Brazil). The patients selected for this study had an indication for extraction of mandibular third molars (MTM) and the risk of inferior alveolar nerve (IAN) injury, as diagnosed on panoramic radiographs (PR). The PR images were obtained in the Rotograph Plus St, (Villa sistemi medicali) with 60$85 \mathrm{Kv}$ range, $5 \mathrm{kV}$ steps, and exposure time of 17 seconds. Inclusion criteria consisted of (1) a close relationship between MTM and MC, (2) at least two thirds of root formation, (3) absence of pathology related to MTM, and (4) age between 18 and 45 years. The patients selected were waiting for third molar extractions in the Department of Oral Surgery of the School of Dentistry of Bauru. The patients who had been indicated for extraction of the third molars and needed cone beam computed tomography $(\mathrm{CBCT})$ were included in the sample. The age range of these patients who met the inclusion criteria varied from 18 to 45 years. Patients under 18 years old may not have two-thirds of root formation, which would significantly reduce the risk of IAN injury. Hence, patients under 18 years old were excluded from the sample, but their treatment was performed later without CBCT images.

This study included 20 teeth from 16 patients with close contact between MTM and MC. The Research Committee of the university approved the protocol in accordance with the Declaration of Helsinki. After the signatures of written consent, the patients were invited to do a CBCT exam with the following protocol:

- Field of view: mandible;

- 0.3-mm voxel;

- Focal point: $0.5 \mathrm{~mm}$;

- $120 \mathrm{~V}$;

- $18.45 \mathrm{mAs} ;$

- Scan time: $20 \mathrm{~s}$.

The exams were performed in the $\mathrm{i}-\mathrm{CAT}^{\mathrm{TM}}$ (Classic Imaging Science International Hatfield, Pennsylvania, USA).

\section{Surgical procedure}

After the imaging exams, an oral and maxillofacial surgeon performed the surgeries of the patients under local anesthesia with $2 \%$ articaine with 1:200,000 epinephrine (DFL $\left.{ }^{\mathrm{TM}}\right)$. For osteotomy and tooth sectioning, \#6 and \#8 carbide burs were used. During the procedure, the surgeon verified whether there was an exposure of IAN. After 15 days of postoperative period, the surgeon verified whether there was presence or absence of paresthesia by touching the lower lip.

\section{Imaging analysis}

All PRs were digitalized with a HP Scanjet G4050 ${ }^{\mathrm{TM}}$ scanner. In a darkened room, the PRs of all patients were displayed randomly. A trained oral radiologist performed the evaluation on a 17 " PC monitor. The PRs were assessed using a software (HP MediaSmart Photo Main Program). The position of the inferior alveolar canal (IAC) in relation to the third molar was classified as type 1 - interruption of the white line of the mandibular canal wall, type 2 - darkening of roots, type 3 - diversion of the mandibular canal, type 4 - narrowing of roots. After 30 days, the same oral radiologist evaluated the CBCT exams. The CBCT image evaluations were conducted by the same trained oral radiologist in a darkened room on a 20" PC monitor (FlexScan $\mathrm{S} 2000^{\mathrm{TM}}$, Eizo Nanao Corporation Hakusan, Japan) using a software (i-CAT VisionE ${ }^{\mathrm{TM}}$ ). The implant-planning screen and the multiplanar reconstruction screen were used to scroll through the axial, sagittal, and coronal planes. The slice thickness was $1 \mathrm{~mm}$. The buccolingual relationships of the $\mathrm{MC}$ in relation to the roots of the third molar, as observed on CBCT images in sagittal, transversal, and coronal dimensions, were classified as lingual, buccal, interradicular, or inferior. Therefore, the CBCT images were classified as presence or absence of bone contact between MTM and MC. The oral radiologist was blinded for the clinical outcome.

\section{Statistical analyses}

Cramer's V coefficient was calculated for intra-observer agreement. This method was interpreted as follows: less than or equal to 0.40 - poor agreement, 0.40-0.59 - moderate agreement, 0.60-0.74 - good agreement, and 0.75-1.00 - excellent agreement. The data analysis considered the association between the PR findings (type 1 , type 2 , type 3 , and type 4) and CBCT findings (presence/absence of bone contact between MTM and MC). Correlation between PR and CBCT images was evaluated using Fisher's exact test, at significance level of $p<0.05$.

\section{Results}

The study included 10 men $(62.5 \%)$ and 6 women $(37.5 \%)$, and 20 teeth (in 16 patients) were analyzed. The average age of the 16 patients participating was $27.1 \pm 6.6$ years. Intra-observer agreement was excellent for both imaging methods, according to Cramer's V coefficient (observer: 0.9 for PR and 0.95 for CBCT). There was a significant association between the darkening of roots (type 2) and the absence of bone contact between mandibular third molar (MTM) and mandibular canal (MC) $(p=0.031992$; Table 1). 
Table 1 - Association between panoramic radiograph images and cone beam computed tomography images

\begin{tabular}{c|c|r|r|r|r}
\hline $\begin{array}{c}\text { PR } \\
\text { images } \\
\text { (PR) }\end{array}$ & $\begin{array}{c}\text { Number } \\
\text { of cases } \\
\text { (PR) } \\
\mathrm{n} / \%\end{array}$ & $\begin{array}{c}\text { Presence } \\
\text { of bone } \\
\text { contact } \\
\text { (CBCT) } \\
\mathrm{n} / \%\end{array}$ & $\begin{array}{c}\text { Absence } \\
\text { of bone } \\
\text { contact } \\
\text { (CBCT) } \\
\mathrm{n} / \%\end{array}$ & $\begin{array}{c}\text { IAN } \\
\text { exposure } \\
\mathrm{n} / \%\end{array}$ & \multirow{2}{*}{} \\
\hline Type 1 & $9(45.0)$ & $8(40.0)$ & $1(5.0)$ & 0 & 0.318885 \\
Type 2 & $4(20.0)$ & $1(5.0)$ & $3(15.0)$ & $1(5.0)$ & $\mathbf{0 . 0 3 1 9 9 2 *}$ \\
Type 3 & $4(20.0)$ & $3(15.0)$ & $1(5.0)$ & 0 & 1 \\
Type 4 & $3(15.0)$ & $3(15.0)$ & 0 & 0 & 0.539474
\end{tabular}

Notes: PR: panoramic radiograph; CBCT: cone beam computed tomography; IAN: inferior alveolar nerve; *: Statistically significant difference, $p<$ 0.05 ; Type 1: interruption of the white line of the mandibular canal wall; Type 2: darkening of roots; Type 3: diversion of the mandibular canal; Type 4: narrowing of roots.

Source: authors.

No significant association was found between other panoramic radiograph (PR) images (type 1, type 3 , and type 4 ) and the presence or absence of cortical bone between MTM and MC (Table 1). There was one case with exposure of inferior alveolar nerve (IAN), but without injury. The PR image found in this case was type 2 (darkening of roots). The cone beam computed tomography (CBCT) image found in this case was inferior with absence of bone contact (Figure 1).
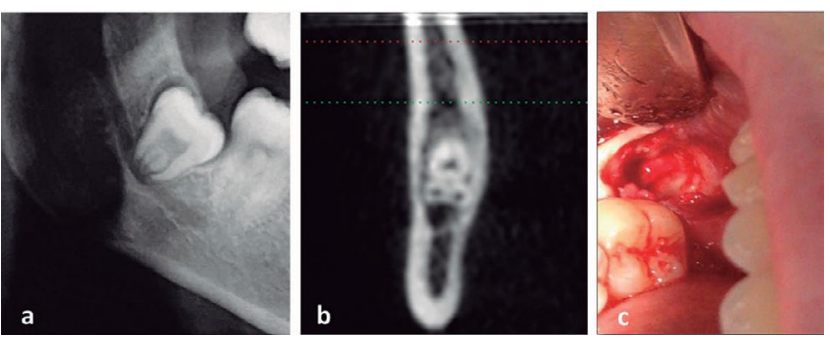

Figure 1 - Association between imaging and clinical findings

Notes: a) Panoramic radiograph image - type 2 (darkening of roots); b) Cone beam computed tomography image - inferior type and the absence of bone contact between mandibular third molar and mandibular canal; c) Inferior alveolar nerve exposure.

Source: authors.

Table 2 shows the buccolingual relationship of the MC and the roots of the third molar, as observed on CBCT images and by the IAN exposure.

Table 2 - Cone beam computed tomography images and inferior alveolar nerve exposure

\begin{tabular}{l|r|r}
\hline \multicolumn{1}{c|}{ CBCT images } & $\begin{array}{r}\text { Number of cases } \\
\mathrm{n} / \%\end{array}$ & $\begin{array}{c}\text { IAN exposure } \\
\mathrm{n} / \%\end{array}$ \\
\hline Lingual & $1(5.0)$ & 0 \\
Buccal & 0 & 0 \\
Interradicular & 0 & 0 \\
Inferior & $19(95.0)$ & $1(5 \%)$ \\
\hline
\end{tabular}

Notes: CBCT: cone beam computed tomography; IAN: inferior alveolar nerve. Source: authors.

\section{Discussion}

It has been reported that the most important factor for inferior alveolar nerve (IAN) injury is the anatomical relationship between the impacted third molar and the inferior alveolar canal (IAC) ${ }^{13,14}$. However, other authors have emphasized that multiple factors, including surgeon experience, surgical technique, institutional setting, and anatomical and radiographic factors are associated with an increased risk of IAC damage ${ }^{15,16}$.

In our study, there was only one case with exposure of IAN. The cone beam computed tomography (CBCT) image found in this case was inferior with absence of bone contact between mandibular third molar (MTM) and mandibular canal (MC) (Figure 1). Although the absence of bone contact between MTM and MC may be highly suggestive of IAN exposure during surgery (which has been associated with a high risk of IAN injury), reports indicate a chance of $20 \%$ of postoperative paresthesia with $70 \%$ of chance of recovery one year after the surgery ${ }^{17}$. Other authors ${ }^{15,16}$ emphasize that both image findings and surgeon experience (and surgical technique) were related with an increasing risk of injury. Considering the proximity of MTM with MC, a technique with osteotomy and tooth sectioning was selected. This technique aimed to prevent the use of excessive force in order to preserve the integrity of the IAN. There was no paresthesia in this case, which proved that choosing the most adequate surgical technique might prevent IAN injury even in the case of high risk ${ }^{15-17}$. The mandible shows a sexual growth dimorphism, growing larger and for a longer time in men than in women. In the present study, the case of IAN exposure after surgery occurred in a female patient. However, the factor that could explain the close contact between MTM and $\mathrm{MC}$ is the degree of impaction of the MTM. The greater the depth of the MTM the greater is the chance of intimate contact between such tooth and MC. In this case, the third molar was deepest than all extracted teeth and the MC had a lower position in relation to the tooth (CBCT finding). Both factors led to IAN exposure after extraction.

In four other cases, there was absence of bone contact between MTM and MC, but none of them showed IAN exposure (Table 1). This could be explained by tooth angulation and the impossibility of seeing the tooth socket. In $60 \%$ of cases with absence of bone contact between MTM and MC, the corresponding PR image was type 2 (darkening of roots). This data was statistically significant (Table 1 ) and it is in accordance with Peker ${ }^{12}$. In one case $(20 \%)$, the corresponding PR image was type 1 (interruption of the white line of the mandibular canal wall) (Figure 2). 


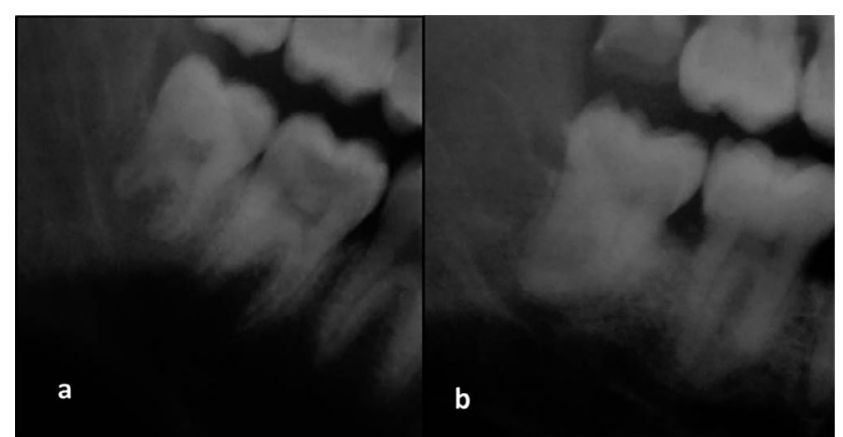

Figure 2 - Radiographic findings suggesting close contact between mandibular third molar and mandibular canal

Notes: a) Interruption of the white line of the mandibular canal wall, b) Diversion of the mandibular canal.

Source: authors.

In the other case (20\%), the corresponding PR image was type 3 (diversion of the mandibular canal) (Figure 2). When analyzing these data, some aspects should be considered. First, the sample included 20 teeth, which composed $20 \%$ of the PR sample of patients that were waiting for third molar surgery. Therefore, it could be observed that in most cases, there is no risk of IAN injury based on PRs. Others studies ${ }^{18-20}$ reported that in $56.4 \%$ of cases (most cases), there was no risk of IAN injury. However, the sample included 133 teeth and the rate of teeth without risk of IAN injury was slightly higher than teeth with such risk. According to Hasani ${ }^{20}$, CBCT may provide excellent diagnostic accuracy in detecting IAN exposure. The PR also showed a satisfactory positive predictive value, meaning that the presence of at least one of the risk factors evaluated (particularly narrowing of inferior alveolar canal and darkening of roots) should be taken seriously. In the present study, the only case with IAN exposure was type 2 (darkening of roots), which corroborates a previous study ${ }^{18}$. A meta-analysis aggregating the raw data from previous studies calculated a sensitivity of $53.5 \%$ for interruption of the cortical border, $51.2 \%$ for darkening of roots, and $29.4 \%$ for canal diversion ${ }^{19}$. In the present study, the three PR images associated with a higher risk of IAN exposure (absence of bone contact between MTM and MC) were the same from a previous study ${ }^{20}$ (Table 1). According to Ghaeminia ${ }^{11}$, whose work didn't involve surgical procedure, the evaluation IAN injury risk based on CBCT was lower than the same evaluation based on PRs. The buccolingual relationship of the MC and the roots of the third molar would allow determining the direction of tooth luxation. For instance, if the MC was located in a lingual aspect in relation to the MTM, tooth luxation would occur in the direction of the buccal plate. If the MC was located in a buccal aspect in relation to the MTM, tooth luxation would occur in the direction of the lingual plate. This buccolingual relationship of the mandibular canal in relation to the roots of the third molar may not be seen in PRs. Hence, after analyzing this proper relation (CBCT) and after determining the correct surgical approach, the authors concluded that there would be a lower risk of IAN injury (CBCT) when compared to PRs.

In the present study, the CBCT image mostly found was the inferior type (Table 2). This data agrees with some authors ${ }^{4,19}$. The CBCT image less found was the interradicular type, as there were no cases with it, which agrees with some authors $\mathrm{s}^{3,4,5,9,19,20}$. This study showed a small variation of the buccolingual relationship of the $\mathrm{MC}$ and the roots of the third molar. Therefore, the most important risk factor in the present study was the absence of bone contact between MTM and MC. However, this risk factor was present in only $5(25 \%)$ cases. There was only one case of IAN exposure, which was identified by the oral radiologist as a risk factor, but without complication of paresthesia.

In the work of Ghaeminia et al. ${ }^{9}$, the IAN paresthesia index was $9 \%$ in a sample including 56 teeth. The significant high IAN paresthesia index found when compared to the present study could be explained by methodology used, anatomical variation, and sample size. In the study of Ghaeminia et al. ${ }^{9}$, two oral surgeons performed the surgical procedures and in the present study, only one oral surgeon performed the surgical procedure, which provided an improved standardization to the results. In the study of Ghaeminia et al. ${ }^{9}$, all anatomical variations were found in the CBCT images (lingual, buccal, interradicular, or inferior). This anatomical variation might be explained by the larger sample size. Although CBCT images elucidate the buccolingual position of the MC in relation to the roots of the third molar, this relationship may not always be clearly identified. Therefore, the higher cost of the CBCT exam compared to PR should be considered before being requested to the surgical planning of third molar surgeries. The main limitation of this study is the sample size and its distribution between female and male patients. Further clinical studies including a larger sample with equal distribution between sex and age are required to establish a more accurate relationship between clinical and imaging findings regarding the risk of IAN injury.

\section{Conclusions}

Based on the findings obtained in this study, it may be concluded that cone beam computed tomography would be best used in surgical planning, when the panoramic radiograph clearly suggests a risk, such as the overlap of the mandibular canal in relation to the third molar roots (darkening of roots). 


\section{Resumo}

Objetivo: são importantes avaliar a posição e estabelecer a relação do terceiro molar com o canal mandibular, para minimizar o risco de lesão do nervo e auxiliar no planejamento da extração desse dente. A radiografia panorâmica é a ferramenta de diagnóstico padrão para esse fim. No entanto, se a radiografia indicar que existe uma relação de contato íntimo entre o terceiro molar e o canal mandibular, pode ser recomendada uma investigação mais aprofundada utilizando a tomografia computadorizada de feixe cônico (TCFC), para verificar a relação tridimensional entre o canal do dente e o canal mandibular. Diante deste contexto, o objetivo deste estudo foi correlacionar os achados clínicos (observados na cirurgia dos terceiros molares inferiores) com os achados imaginológicos (observados na radiografia panorâmica e na tomografia computadorizada de feixe cônico). Sujeitos e método: após a extração de 20 terceiros molares mandibulares, realizou-se a análise da radiografia panorâmica e da tomografia computadorizada de feixe cônico. Em seguida, os achados cirúrgicos foram correlacionados com os achados imaginológicos. Resultados: observou-se que o achado radiográfico do tipo 2 (escurecimento das raízes) observado na radiografia panorâmica foi mais relacionado com a ausência de osso cortical entre o canal mandibular e o terceiro molar (achado da TCFC) sendo estatisticamente significativo ( $p$ $<0,05)$. Conclusões: com base nos achados obtidos neste estudo, pode-se concluir que o TCFC seria mais bem usado no planejamento cirúrgico, quando a radiografia panorâmica sugerir claramente um risco. Ademais, a radiografia panorâmica pode continuar sendo utilizada para planejamento de exodontias de terceiros molares.

Palavras-chave: Dente não irrompido. Radiografia panorâmica. Terceiro molar. Tomografia computadorizada de feixe cônico.

\section{References}

1. Peixoto LR, Gonzaga AK, Melo SL, Pontual ML, Pontual Ados A, de Melo DP. The effect of two enhancement tools on the assessment of the relationship between third molars and the inferior alveolar canal. J Craniomaxillofac Surg 2015; 43(5):637-42.

2. Matzen LH, Wenzel A. Efficacy of CBCT for assessment of impacted mandibular third molars: a review - based on a hierarchical model of evidence. Dentomaxillofac Radiol 2015; 44(1):1-11.

3. Kruse C, Spin-Neto R, Wenzel A, Kirkevang LL. Cone beam computed tomography and periapical lesions: a systematic review analyzing studies on diagnostic efficacy by a hierarchical model. Int Endod J 2015; 48(9):815-28.

4. Spin-Neto R, Gotfredsen E, Wenzel A. Impact of voxel size variation on CBCT - based diagnostic outcome in dentistry: a systematic review. J Digit Imaging 2013; 26(4):813-20.

5. Ishak MH, Zhun OC, Shaari R, Rahman SA, Hasan MN, Alam MK. Panoramic radiography in evaluating the relationship of mandibular canal and impacted third molars in comparison with cone-beam computed tomography. Mymensingh Med J 2014; 23(4):781-6.

6. Nascimento EHL, Oenning ACC, Freire BB, Gaêta-Araujo H, Haiter-Neto F, Freitas DQ. Comparison of panoramic radiography and cone beam CT in the assessment of juxta-apical radiolucency. Dentomaxillofac Radiol 2018; 47(1):115-23.
7. Nascimento EH, Oennnig AC, Rocha Nadaes M, Ambrosano GM, Haiter-Neto F, Freitas DQ. Juxta-apical radiolucency: relation to the mandibular canal and cortical plates based on cone beam CT imaging. Oral Surg Oral Med Oral Pathol Oral Radiol 2017; 123(3):401-7.

8. Haas LF, Dutra K, Porporatti AL, Mezzomo LA, De Luca Canto G, Corrêa M. Anatomical variations of mandibular canal detected by panoramic radiography and CT: a systematic review and meta-analysis. Dentomaxillofac Radiol 2016; 45(2):20150310.

9. Shah NP, Murtadha L, Brown J. Bifurcation of the inferior dental nerve canal: an anatomical study. Br J Oral Maxillofac Surg 2018 7. Pii:S0266-4335(18)30037-8.

10. Neves FS, Nascimento MC, Oliveira ML, Almeida SM, Bóscolo FN. Comparative analysis of mandibular anatomical variations between panoramic radiography and cone beam computed tomography. Oral Maxillofac Surg 2014; 18(4):419-24.

11. Rodriguez Y, Baena R, Beltrami R, Tagliabo A, Rizzo S, Lupi SM. Differences between panoramic and Cone Beam - CT in the surgical evaluation of lower third molars. J Clin Exp Dent 2017; 9(2):e259-e265

12. Peker I, Sarikir C, Toraman M, Zor ZF. Panoramic radiography and cone-beam computed tomography findings in preoperative examination of impacted mandibular third molars. BMC Oral Health 2014; 14:71.

13. Fee PA, Wright A, Cunningham C. Cone beam computed tomography in pre-surgical assessment of mandibular third molars. Evid Based Dent 2016; 17(4):117-8.

14. Matzen LH, Schropp L, Spin-Neto R, Wenzel A. Radiographic signs of pathology determining removal of an impacted mandibular third molar assessed in a panoramic image or CBCT. Dentomaxillofac Radiol 2017; 46(1):20160330.

15. Eyrich G, Seifert B, Matthews F, Matthiessen U, Heusser $\mathrm{CK}$, Kruse AL, et al. 3-Dimensional imaging for lower third molars: is there an implication for surgical removal? J Oral Maxillofac Surg 2013; 69:1867-1872.

16. Lübbers HT, Matthews F, Damerau G, Kruse AL, Obwegeser JA, Grätz KW, et al. No plane is the best one-the volume is! Oral Surg Oral Med Oral Pathol Oral Radiol 2013; 113:421.

17. Oenning AC, Neves FS, Alencar PN, Prado RF, Groppo FC, Haiter-Neto F. External root resorption of the second molar associated with third molar impaction: comparison of panoramic radiography and cone beam computed tomography. J Oral Maxillofac Surg 2014; 72(8):144-55.

18. Guerrero ME, Botetano R, Beltran J, Horner K, Jacobs R. Can Preoperative imaging help to predict postoperative outcome after wisdom tooth removal? A randomized controlled trial using panoramic radiography versus cone-beam CT. Clin Oral Invest 2014; 18(1):335-42.

19. Muinelo-Lorenzo J, Suárez-Quintanilla JA, Fernández-Alonso A, Marsillas-Rascado S, Suárez-Cunqueiro MM. Descriptive study of the bifid mandibular canals and retromolar foramina: cone beam CT vs panoramic radiography. Dentomaxillofac Radiol 2014; 43(5):20140090.

20. Ghaeminia H, Gerlach NL, Hoppenreijs TJ, Kicken M, Dings JP, Borstlap WA, et al. Clinical relevance of cone beam computed tomography in mandibular third molar removal: A multicentre, randomised, controlled trial. J Craniomaxillofac Surg 2015; 43(10):2158-67.

\section{Corresponding author:}

Josfran da Silva Ferreira Filho

Rua Dona Leopoldina, 1045

ZIP Code: 60110-000, Ceará, Fortaleza, Brazil

Phone: +55 88997623464

E-mail: josfranf@hotmail.com

Recebido: 08/01/18. Aceito: 20/03/18. 